\title{
Deposit Formation in the Holes of Diesel Injector Nozzles: A Critical Review
}

\author{
A. Birgel, N. Ladommatos, P. Aleiferis \\ University College London
}

\author{
S. Zülch, N. Milovanovic, V. Lafon, A. Orlovic, P. Lacey
}

Delphi Diesel Systems

P. Richards

Innospec Limited

\begin{abstract}
Current developments in fuels and emissions regulations are resulting in increasingly severe operating environment for the injection system. Formation of deposits within the holes of the injector nozzle or on the outside of the injector tip may have an adverse effect on overall system performance. This paper provides a critical review of the current understanding of the main factors affecting deposit formation.
\end{abstract}

Two main types of engine test cycles, which attempt to simulate field conditions, are described in the literature. The first type involves cycling between high and low load. The second involves steady state operation at constant speed either at medium or high load.

A number of influences on the creation of deposits are identified. This includes fouling through thermal condensation and cracking reactions at nozzle temperatures of around $300^{\circ} \mathrm{C}$. Also the design of the injector holes is an influence, because it can influence cavitation. The implosion of cavitation bubbles is believed to limit nozzle deposits. Field and laboratory tests showed that small amounts (around 1ppm) of zinc tend to increase the formation of deposits and are therefore another influence. But it is not clear whether zinc acts catalytically to accelerate deposit formation or if it becomes part of the solid deposits. Bio-diesel has been observed to lead to higher deposit formation in the injector nozzle.

The chemical and physical processes that lead to deposit formation are not known or well understood, due to their complexity. A physical mechanism put forward focuses on the role of the residual fuel that remains in the nozzle holes after the end of the injection process.

\section{INTRODUCTION}

The strict emissions limits (EURO 4, EURO 5) exert legal pressure on manufacturers to improve the fuel economy and reduce the $\mathrm{CO}_{2}$ emissions of passenger cars. This pressure level leads to a highly optimized design of injectors for diesel engines. The design of the nozzle is constantly improved to produce a better diesel spray quality and a deeper spray penetration in the combustion chamber by for example raising the injection pressures and improving the design of the injection holes.

However it seems that this improved design of the injection holes leads to a more critical problem in injector coking and fouling. This phenomenon produces deposits in the injector holes and on the outside of the injector tip. It seems that alternative fuels increase this phenomenon, as shown in Figure 1 for pure biodiesel and Figure 2 for blends of biodiesel.

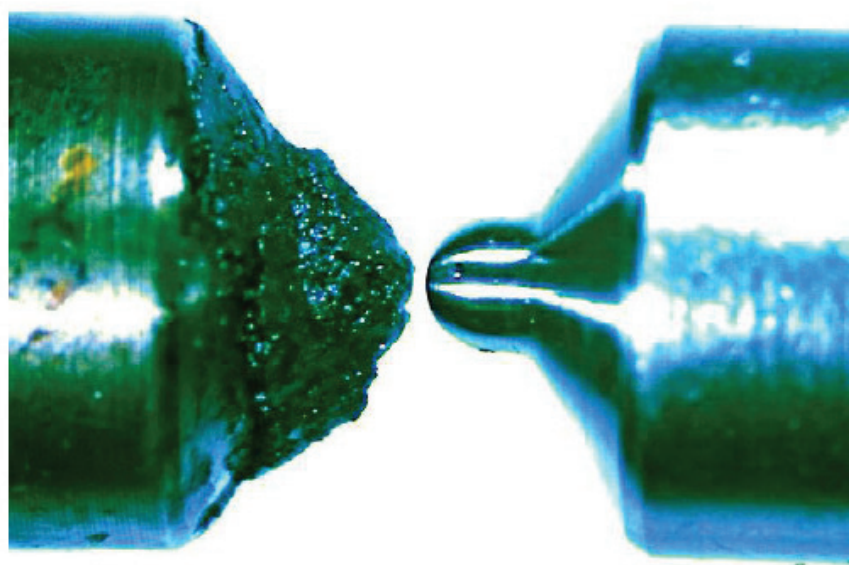

Figure 1: The example of deposits on injector tip from an engine fuelled with rapeseed biodiesel [1]. 
Biodiesel is taken to mean a blend of fatty acid methyl esters (FAME) derived from bio sources. Current increased interest in these alternative fuels, like rapeseed oil, biodiesel and their blends with diesel fuel, could cause undesired interactions with highly optimized powertrain designs.

The deposits, especially in the orifices reduce the hydraulic diameter and hence the hydraulic flow in the nozzle. Thus the amount of injected fuel is decreased and the spray quality is considerable reduced. This leads to higher fuel consumption and deteriorated combustion so that the exhaust emissions increase. Such influences have already been reported in the literature [2-4].

Indeed, a considerable amount of research has been done to improve the spray quality and to understand the main influences on this quality, such as cavitation. Much less attention has been devoted to understanding the mechanisms of injector fouling with diesel, biodiesel and their blends such as B5, B10 or B20. These respectively represent blends of 5,10 or $20 \%$ by volume of biodiesel with petroleum diesel. Since in most of the EU member countries blends of biodiesel are going to be mandatory, it is of considerable importance to understand this phenomenon.

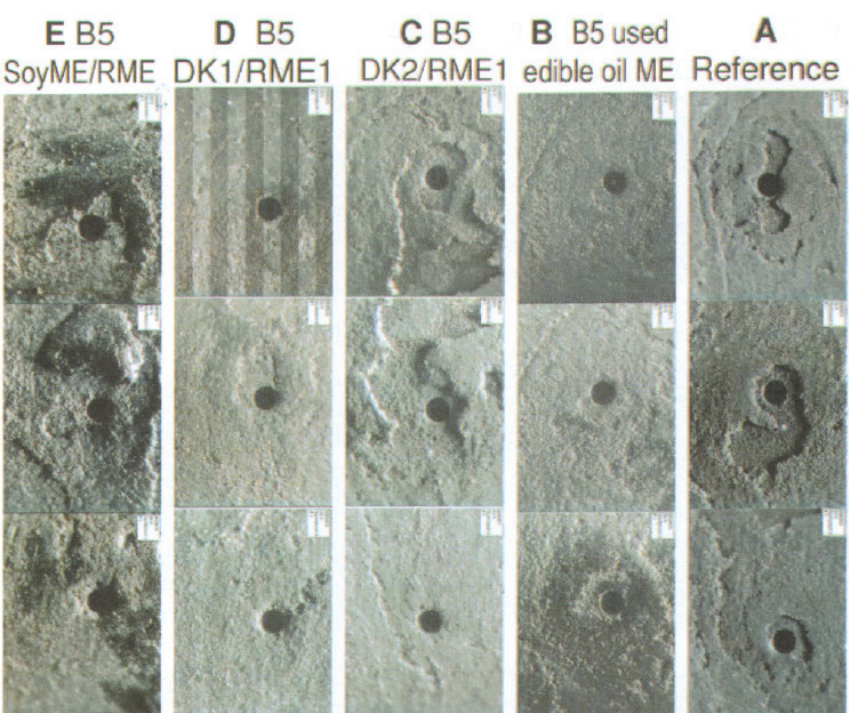

Figure 2: Example of different amounts of deposits on diesel injectors from several engines running on different types of biodiesel blends [5]. Descriptions of fuels see Table 1.

This paper first shows the different types of test cycles used to create deposits on the injector. Also methods used for optical investigations of these deposits are shown. After that the influences of fuel type and composition, nozzle geometry and temperature on injector coking are described and discussed. Lastly a physical mechanism that leads to injector coking is described.

\section{TEST CYCLES AND OPTICAL INVESTIGATIONS}

In general there are two different types of engine test schedules that have been used to produce deposits on injectors.

The first type includes high load operating points to create high temperatures at the injector tip, followed by low load operating points. The most common ones are known as the XUD-9A test cycle, the Cummins L10 injector test, the Ford Puma test cycle and the DW10 test cycle. Versions of this type of test were used in references e.g. by [5-14]. Hawthorne et al. [15] comment on the severity of the test conditions of the DW10 test procedure relative to what is encountered in the field. They conclude that "during the DW10 test injectors are subject to a cumulative period of high speed or high load conditions equivalent to what a vehicle would experience over a full life time." Therefore this cycle seems to be sufficient to reproduce the conditions experienced from an engine used in a consumer vehicle.

The other type of test consists of engine runs at constant speed and load (both medium to high) for a longer period of time. This may also enable investigations of the influence of different engine and injection operating parameters as it keeps the flow conditions in the nozzle constant. Different versions of this type of test were used in references $[2,3,16,17]$.

These test cycles are used to produce deposits on the injectors and to investigate their influence on the engine performance. Most common is to observe the power or torque loss of the engine during the cycle. The cycles are also used to investigate the different influences such as fuel composition and additives, on diesel injector deposits which are discussed in the next section.

Furthermore after the tests the injectors can be used for optical investigations. The paper by Sem [1] gives a visual comparison of injectors run on pure biodiesel (rapeseed methyl ester (RME) and soybean methyl ester (SME)) and diesel, to show that running on biodiesel creates a larger amount of deposits on the outer surface of injector nozzles, see Figure 1. Optical investigation of the amount of the deposits on injector nozzles is described in papers [18, 19]. In these papers the injectors were photographed and the visible amount of deposits was calculated. Fuels were D2 diesel, different safflower oils, and blends of these [19] as well as oxygenated diesel [18]. However these papers do not investigate any influences on the creation of deposits. An image analysis system for the test applied in [10] is described in [14]. 


\section{EFFECTS OF FUEL COMPOSITION}

\section{Diesel fuel}

Several papers, published by Caprotti et. al. [6-8] discuss the influence of the fuel composition on deposits in modern diesel injector systems. These papers describe several tests to evaluate the development of deposits in injectors with the dependence of the diesel fuel quality as a main influence. In order to increase and accelerate the build-up of deposits different amounts of soluble zinc were added to the fuel and a defined test procedure was performed. This was done since laboratory and field tests showed that some acid-based fuel additives force the uptake of zinc out of the fuelling system components of cars [6].

The bench engine test cycle that was used for an advanced injection systems is described in [9]. These advanced injection systems are "characterised by a high fuel pressure and small spray holes". The cycle is supposed to produce high temperature at the injector nozzles, so that more deposits are produced. Several operating points are run during an 8 hours endurance test, followed by an 8 hour soaking period and another 8 hour endurance test. The soak period allows friable deposits to fall off and the engine to cool down. Therefore, after the restart, several deposits may be removed due to thermal stresses. The operating points of the test procedure are shown in Figure 3 . It consists of different operating points at low speed / low load as well as high speed / full load. By comparison of power and speed measurements before and after the test, the amount of deposits created can be assessed by the loss of power.

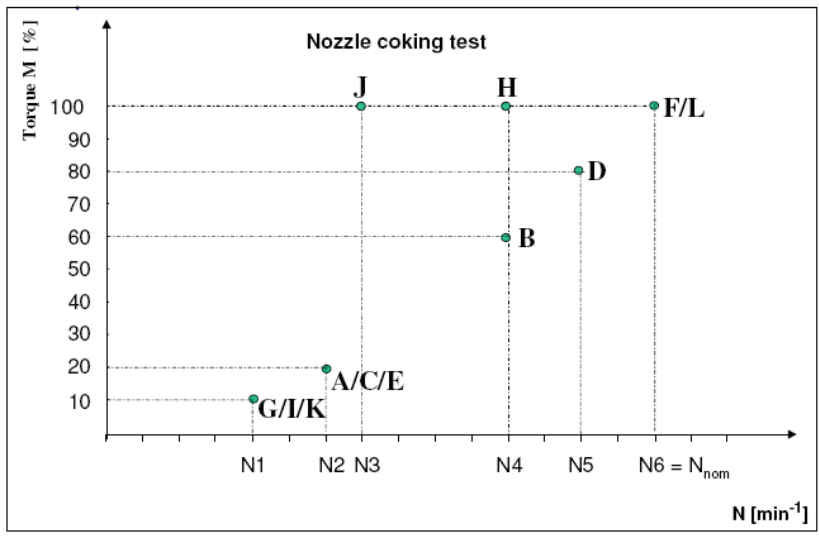

Figure 3: The operating points with appropriate speed and torque for deposits test procedure by [9]

With this test procedure Caprotti et. al. [6-8] show that an increasing amount of zinc leads to increasing amounts of deposits. The amounts of deposits are assessed by the power loss of the engine and fuel flow loss at a constant injector pulse width, see Figure 4. For the repeatability of the test method see Figure 5; and for the correlation between the amount of zinc and the required test time see Figure 6.

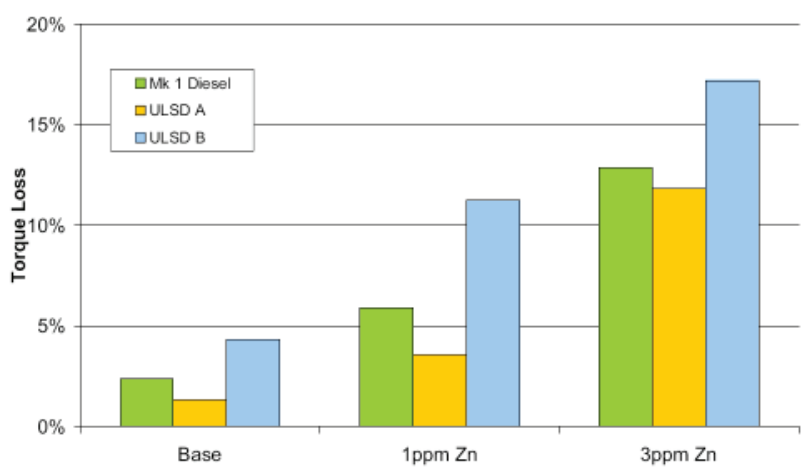

Figure 4: The response in torque loss to $\mathrm{Zn}$ in different fuels in engine tests [8]

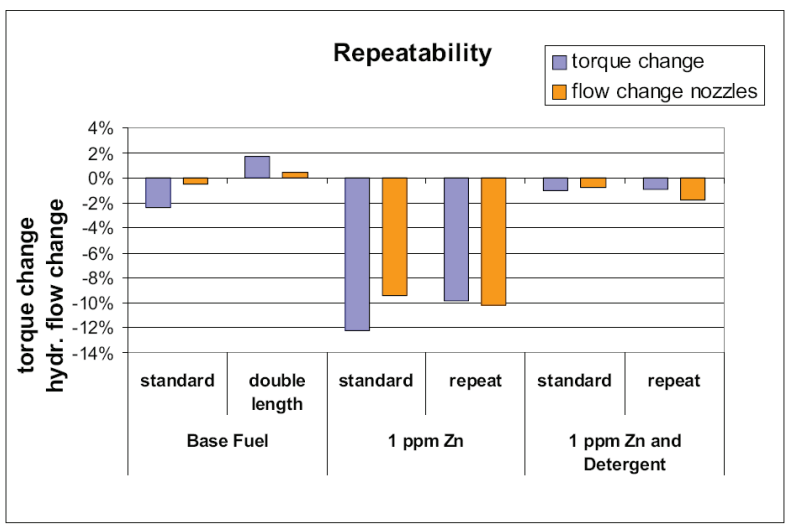

Figure 5: Repeatability of test protocol used by [8]

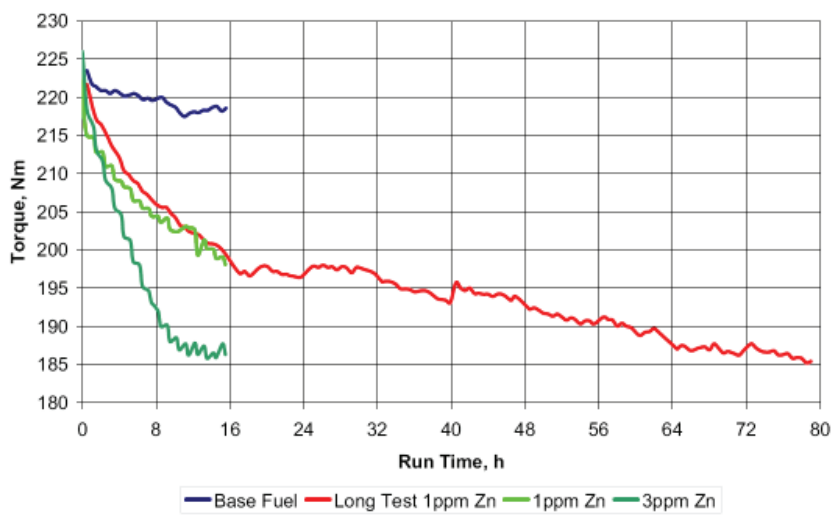

Figure 6: Impact of different amounts of zinc and test time on torque loss in engine tests [8] 
Scanning Electron Microscope and Energy Dispersive XRay Analysis (SEM-EDX) showed that the deposits, which were built up by fuels with different amount of $\mathrm{Zn}$ in the fuel contain the same amount of zinc. Caprotti et. al. [8] deduced that: "As the hydraulic flow loss, the power loss and the composition of the deposits are similar [irrespective of the amount of $\mathrm{Zn}$ in the fuel], this supports the fact the mechanism responsible for the formation of the deposit is the same and independent from the level of $\mathrm{Zn}$ present in the fuel."

The point of view, that the zinc is acting as a catalyst for the normal depositing mechanism is questioned in a paper from Barbour et. al. [20]. This paper investigates the sensitivity to deposits of different engines with different test cycles and zinc doped fuels. Three engines with individual test procedures were compared.

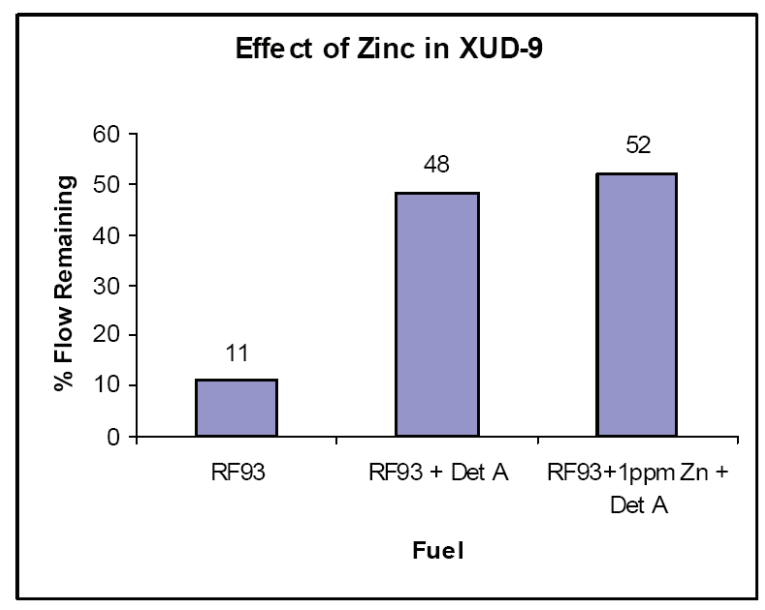

Figure 7: The effect of zinc in XUD-9A engine deposit test [20]

The first engine was the indirect injection (IDI) XUD-9 engine from PSA and used the standard CEC F-23-01 test procedure. This engine and the test procedure are well understood but the engine design is very old. The second engine was the turbocharged Ford Puma engine which used a conventional, distributor pump injection system. It was claimed that "this system is extremely close to a common-rail system without actually being one" [20]. The test cycle was also developed by the CEC but this cycle requires zinc added to the fuel to produce deposits and the engine is not representative for the current market. The third engine was the DW10 engine from PSA with a modern common rail injection system. This engine specification and its associated test procedure are being developed by the CEC, and they were also used by [8] and [9].

These different tests with different engines indicate that modern engines with a direct injection (DI) common-rail system react differently to older IDI engines operating on different fuels, different amounts of zinc and different additives.
Figure 7 shows that, in the XUD-9A, the change in the injector flow loss between the test with "base fuel RF93 + Detergent A" and the test with "base fuel RF93 + Detergent $A+1 \mathrm{ppm} Z \mathrm{Zn}$ " is less than to the test with pure "base fuel RF93". This shows that the XUD-9 engine deposit build-up is less susceptible to zinc in the fuel.

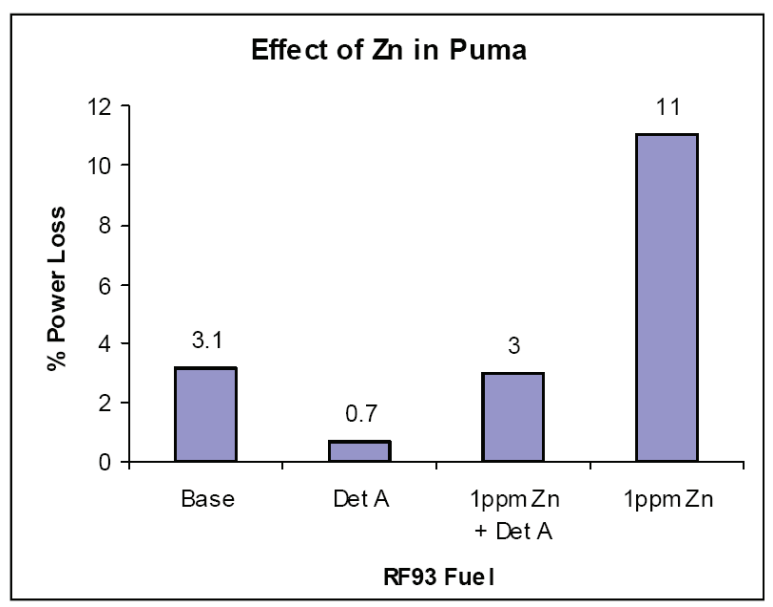

Figure 8: The effect of zinc in Ford Puma engine test [20]

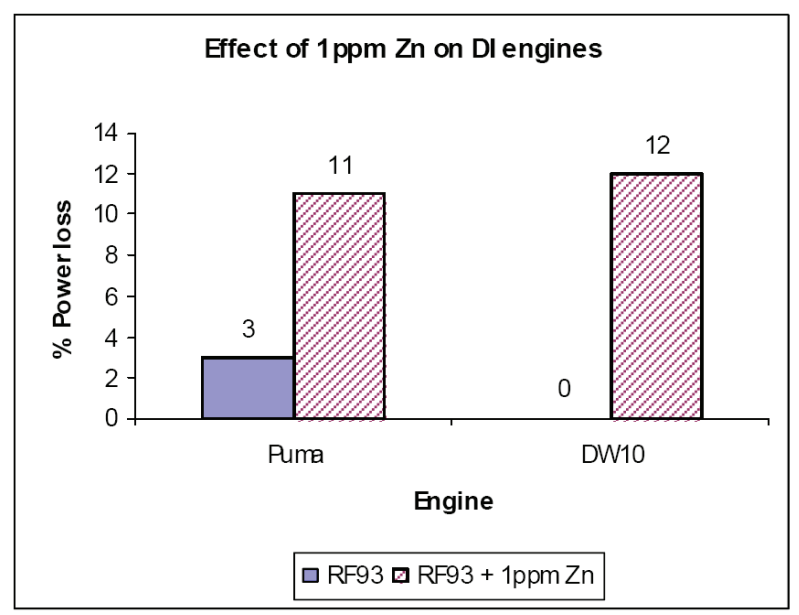

Figure 9: The effect of zinc on DI engines [20]

The test with the Ford Puma engine and the DW10 (Figure 8 and Figure 9) show that modern engines are more affected by zinc contaminated fuel than the older XUD-9A engine.

In reference [20] the influence of zinc on the mechanism for the creation of deposits was investigated through an analysis of the injector deposits at the end of the test. It was reasoned that with the use of zinc, a "possible mechanism is that zinc is acting as an accelerant or catalyst for the normal deposit processes and would exaggerate the normal mechanism of injector fouling." As a critical point on that, it is mentioned that market 
fuels normally do not contain significant amounts of zinc. Furthermore the deposits of three injectors used in the DW10 were analysed using Electron Dispersive Spectroscopy (EDS).

The fuels used and their power losses were as follows:

Injector 1: base fuel RF93 + 1ppm Zn

$9.2 \%$

Injector 2: base fuel RF93 + 1ppm Zn + det. A $\quad 4.6 \%$

Injector 3: B10 biodiesel

$3.6 \%$

Figure 10 shows the analysis of the composition of the deposits for the three injectors [20]. The figure shows that zinc accounted for up to $31 \%$ of the deposits in injector number 1 , up to $25 \%$ of deposits in injector number 2 and significant lower content in injector 3 .

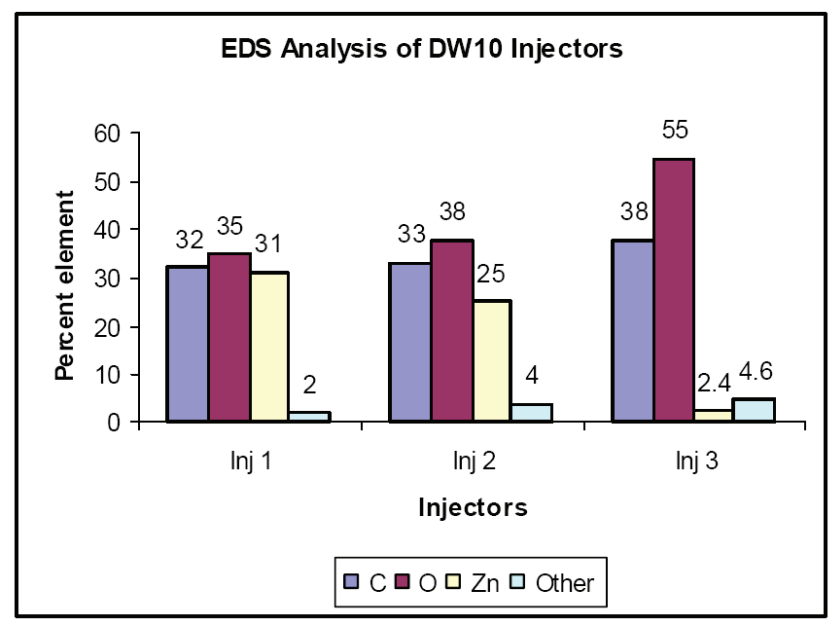

Figure 10: EDS Analysis of DW10 Injectors [20]

Barbour et. al. [20] "assume that the zinc is present as the oxide" which is the product of the burning of zinc by combustion. In contrast the paper by Caprotti et. al. [8] states the belief that zinc acts as a catalyst aiding deposition. So, if the assumption of Caprotti et. al. is correct, the question raises why zinc is found in the deposits and, furthermore, why should it be in the form of zincoxide. Barbour et. al. [20] assume that the mechanism is not catalytic and that the "zinc appears to be simply depositing on the injector surfaces alongside the normal deposit components". It could be concluded that the knowledge of how zinc aids the formation of deposits should be improved; it is clear from engine tests that zinc does aid the formation of deposits, but the mechanism is not known with any degree of certainty. Hawthorne et. al. [15] caution about "the relevance of using zinc containing base fuels in such a severe cycle needs to be better understood."

\section{Biodiesel and Blends}

Biodiesel and blends with diesel seem to have a different influence on deposits. The analysis by Barbour et al. [20], shown in Figure 10, also demonstrate that the deposits built up by the B10 (10\% biodiesel and $90 \%$ petroleum diesel) have a different chemical composition. They contain a significantly higher amount of oxygen which comes possibly from the higher oxygen content in the biodiesel. This could suggest that biodiesel produces deposits through a different mechanism. Therefore more work should be done to understand the deposits caused by biodiesel and its blends, as there is increasingly more biodiesel used in the market.

The presence of metals, like copper or zinc, has a negative influence on the oxidation stability of biodiesel (PME, palm methyl ester) and its blends [21].

A deeper investigation of the influences of blends of biodiesel on injector coking is combined in the research report from the DGMK (German Society for Petroleum and Coal Science and Technology) [5]. It gives in its first part an extensive chemical investigation program of three different diesel fuels with $5 \%$ and $20 \%$ bio-content of five different FAMEs. The diesel fuels have low, medium and high oxidation stability. The following FAMEs were used: rape seed oil methyl ester (RME 1), aged rape seed oil methyl ester (RME 2), soy bean oil methyl ester (Soy-ME), used edible oil methyl ester (AME) and animal fat (tallow) methyl ester (TME). The whole matrix of these fuels was investigated in addition to the pure fuels.

The main results of these laboratory investigations show that the prediction of the oxidation stability for blends with $5 \%$ biodiesel tends to be very difficult, as shown in Figure 11.

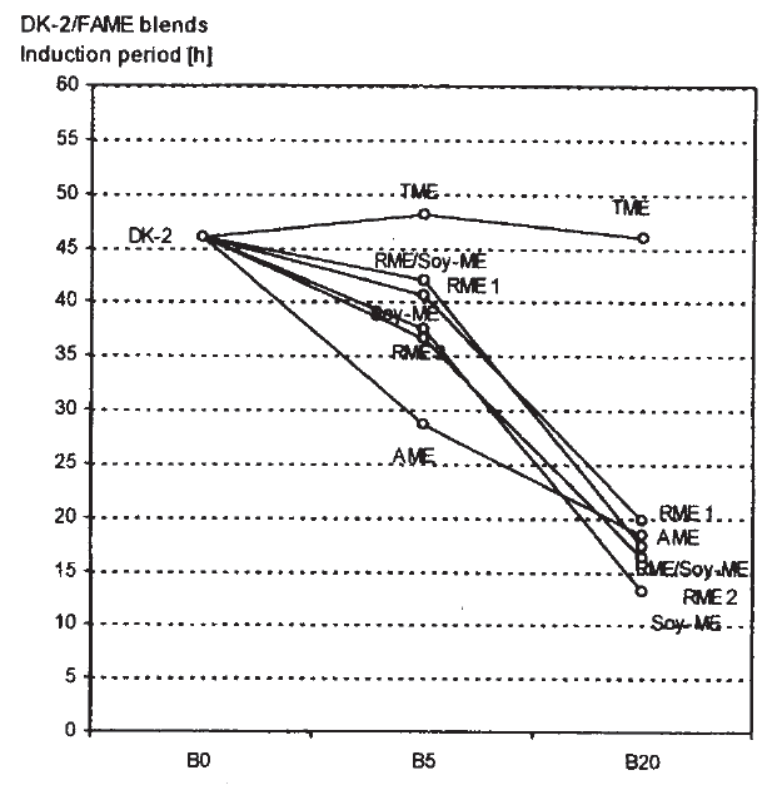

Figure 11: Example for oxidation stability according to DIN EN 14112: Influence of the Addition of FAME [5] 
"These results prove that there are interactions between FAME and diesel fuels, which can cause an incomparable aging behaviour. Therefore, it is difficult to predict the oxidation stability of a B5 blend, even if the induction period of the diesel fuel and FAME is known." [5]. However, with $20 \%$ blends the lower stability of the biodiesel components starts to become a dominating influence, so all blends are showing more consistently lower stability.

The second part of the research report describes coking test runs with four different B5 fuels and a reference fuel on four different modern engines from Audi, BMW, Daimler and VW. Two of these engines were fourcylinder and the remaining two were six-cylinder engines. Two of these engines were operated on a common rail system with solenoid operated injectors; one was operated on a common rail system using piezo injectors and one operated on a pump-nozzle system. The fuels were selected on the basis of the results from the laboratory tests, see Table 1. The paper numbers these four engines 1 to 4 but it does not say which engine corresponds to which number.

Table 1: Test fuels for engine tests done by [5]; (DK= abbr.: Dieselkraftstoff (Ger.); diesel fuel (Eng.))

\begin{tabular}{|c|c|}
\hline $\begin{array}{c}\text { Test fuels } \\
\text { engine test }\end{array}$ & Composition \\
\hline A & $\begin{array}{c}\text { DK1: diesel fuel type 1 (median oxidation stability) } \\
\text { without FAME (reference fuel) }\end{array}$ \\
\hline B & $\begin{array}{r}\text { DK1: diesel fuel type 1 (median oxidation stability) } \\
\text { with 5\% used edible oil methyl ester }\end{array}$ \\
\hline C & $\begin{array}{r}\text { DK2: diesel fuel type 2 (high oxidation stability) } \\
\text { with 5\% RME (rapeseed methyl ester) }\end{array}$ \\
\hline D & $\begin{array}{r}\text { DK1: diesel fuel type 1 (median oxidation stability) } \\
\text { with 5\% RME (rapeseed methyl ester) }\end{array}$ \\
\hline E & $\begin{array}{r}\text { DK1: diesel fuel type 1 (median oxidation stability) } \\
\text { with 5\% RME/Soy-ME (60:40) } \\
\text { (rapeseed methyl ester / soya methyl ester) }\end{array}$ \\
\hline
\end{tabular}

The test cycle combined low loads at low engine speed with high load at high engine speed, so "a typical deposit formation related to field experience can be observed in fast motion." [5]. The test consisted of an 8 hour run time and an 8 hour soaking / cool down period. This makes this test cycle similar to the one being developed by CEC [9]. The engine power output, the smoke number, the exhaust gas temperature, the injected fuel quantity and the target fuel quantity were measured.

Afterwards the deposits formed at the nozzles of the diesel fuel injectors were analysed by light microscope, electron microscope and thermo gravimetric analysis. Additionally the hydraulic flow rate was measured to define the degree of coking. These criteria were weighted and compared so that a ranking was created for the different fuels.
The light microscope images are shown for engine no. 2 in Figure 2. Figure 12 shows the normalized power output progression of one engine for the five different fuels. In Figure 13 the power losses of the engines at the end of the tests are shown. These results show only a significant power loss with fuels $B$ and $D$ operating on engine no. 4. All other engines show a power loss that is "at an uncritical level" [5].

Figure 14 shows the change in the quantity of fuel injected from the start to the end of the test.

The "degree of coking" (Figure 15) is the flow loss of the injector between a non-cleaned and cleaned nozzle expressed as a percentage. Thereafter the "power loss correlates with the decline of injected mass, but not quite with the coking degree" [5]. It also shows that the deposits are mainly influenced by the engine and the fuel but the total amounts of deposits vary.

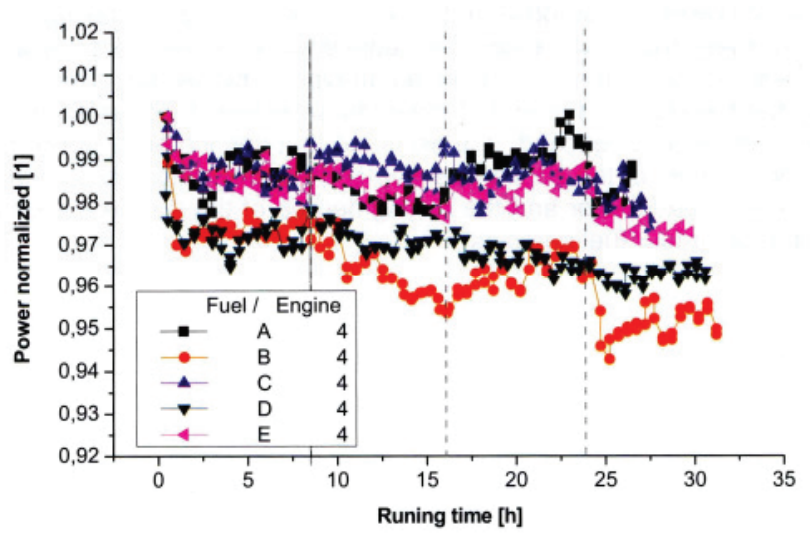

Figure 12: Normalized power output progression for engine no. 4 [5]

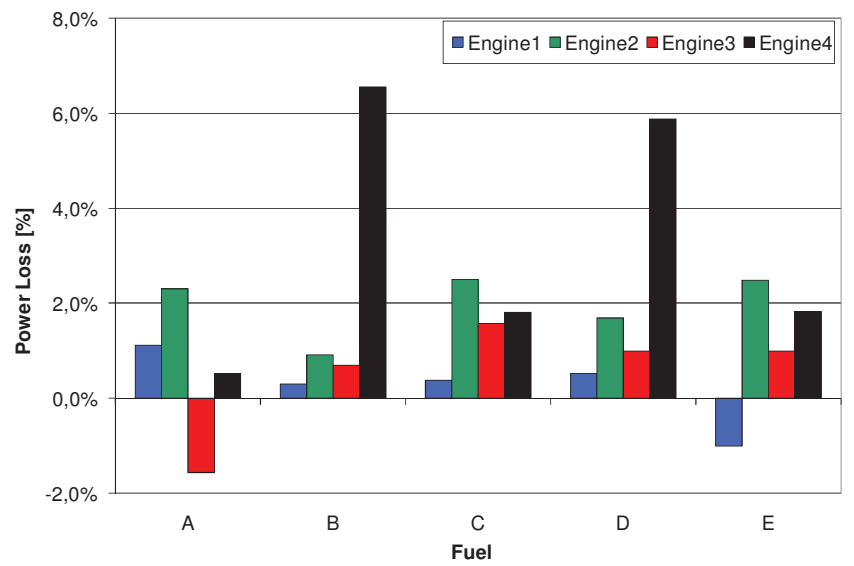

Figure 13: Power losses at end of engine tests [5] 


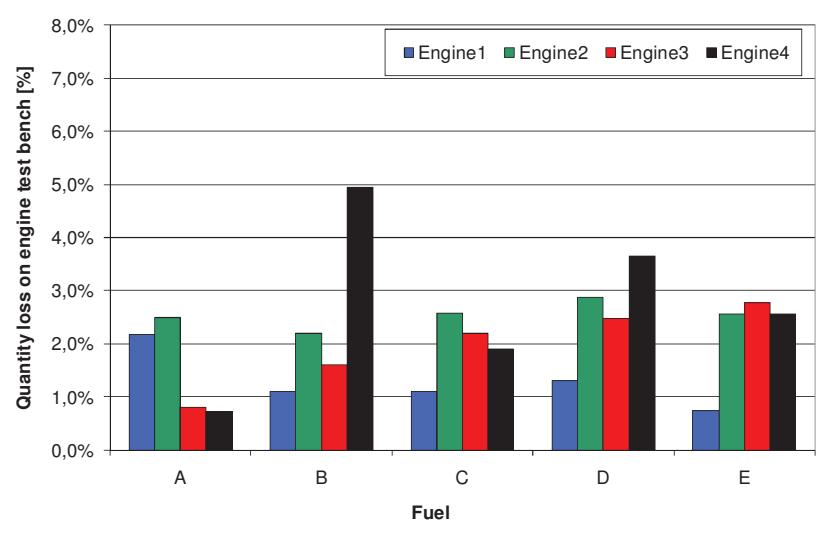

Figure 14: Injected mass reduction at end of engine test [5]

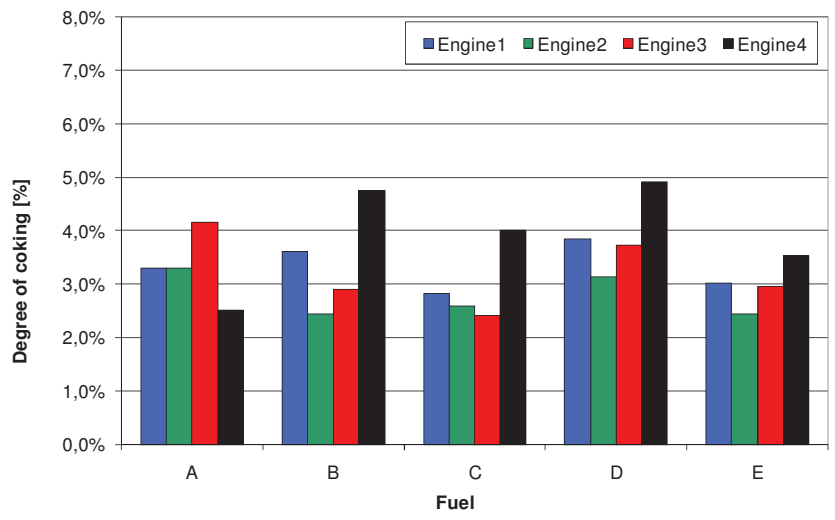

Figure 15: Degree of Coking [5]

Using the data from Figure 13, Figure 14 and Figure 15 the new graphs shown in Figure 16 and Figure 17 were produced. They show power loss and the degree of coking against the injected mass quantity loss. There is only a poor correlation between mass loss and power loss or between mass loss and degree of coking. Furthermore there is a very broad distribution of the measurements. The reasons for these results are probably measurement errors as they are only on a very low percentage.

The above results also demonstrate the importance of not only relying on the engine power loss, but also of investigating the fuel flow loss in the injectors directly, e.g. as described in [22], or of monitoring possible changes in the cylinder pressure trace.

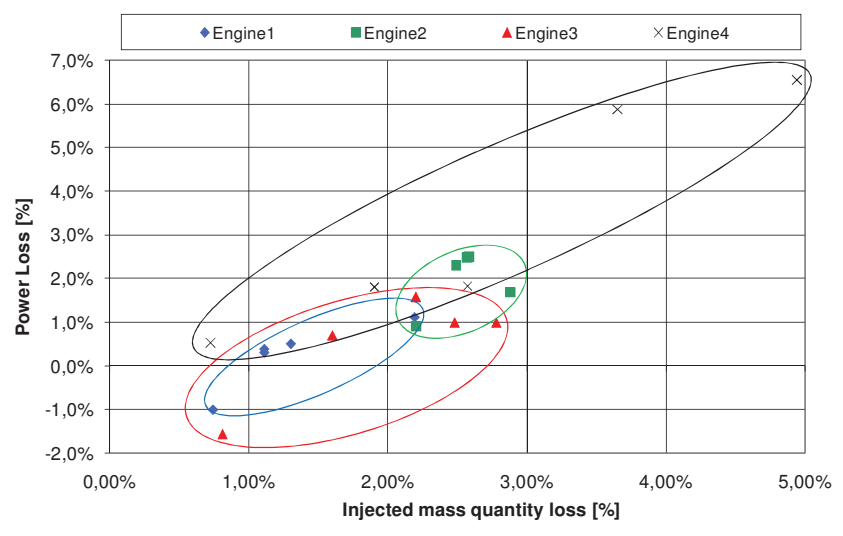

Figure 16: Power loss over injected mass quantity loss; created with [5]

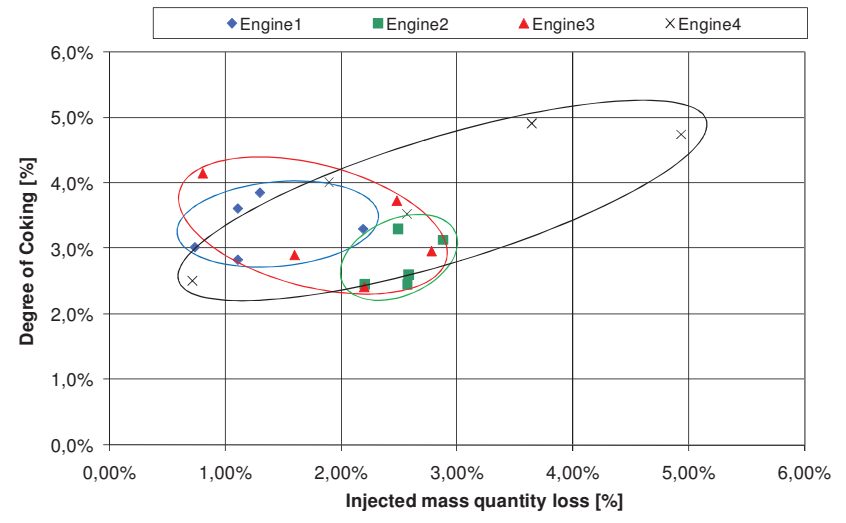

Figure 17: Degree of coking over injected mass quantity loss; created with [5]

The behaviour of B10 was investigated in papers [15] and [23]. In both papers B10 shows a tendency to produce deposits. In [23] it is shown with an IDI XUD-9 engine that test results with the same fuel are repeatable. But it is also shown that different batches of RME, blended to B5, can show a very different behaviour in deposit formation. This demonstrates the different, unpredictable behaviour of different blends of biodiesel, also shown by [5].

Reference [1] shows, that pure biodiesel leads to a certain higher amount of deposits, see Figure 1. The papers [24-28] describe general engine tests with different types of biodiesel and biodiesel blends with normal diesel. A general description of deposits created on the injectors is given but no detailed characterisation or investigation was done. 


\section{$\underline{\text { Additive Treatment }}$}

Increasing legislative and environmental protection requirements, mandatory introduction of oxygenates (fatty acid methyl esters or biodiesel) as diesel fuel extenders and rapid development of diesel engine technology, all make the application of additives inevitable in order to provide "fit for purpose" fuels for modern diesel engines. Modern diesel fuels, and especially premium grade fuels, typically contain the following additive types: antioxidants, corrosion inhibitors, de-emulsification agents, ignition quality or cetane number improvers, improvers of low-temperature flow properties, injector detergents, lubricity additives, antifoam agents and antistatic additives. Since the topic of fuel additives could be covered from different aspects, such as: detailed additive chemistry, functionality, application and potential incompatibilities, we will just briefly outline some of the most recent publications dealing with diesel engine deposits and the role of additives. Very good overviews of additive functionality and chemistry can be found in review papers by Ribeiro et al. [29] and Danilov [30]. Various papers discuss quality improvement of diesel fuels and biodiesel with additives. Generally it could be said that these papers detail investigations into different treatment levels with different detergent additives. They show that there are several additives which will help to reduce the amount of coking during engine tests. Some of them even help to "clean-up" coked nozzles to improve the performance [4, $6,7,9,11,31$ - 35]. Further insight into the structureactivity relationship of diesel fuel detergency additives can be found in paper by Tomlinson et al. [36] while the impact of two common detergent chemistries (polyether amine and polybutene amine) on the structure of carbonaceous deposits has been investigated by Zerda and co-workers [37]. Other diesel fuel additives that have received considerable attention over the past ten years are cold flow improvers and lubricity additives [38, 39].

A very recent paper by Ullmann and co-workers points to diesel injector deposits (sticky polymeric deposits identified as polyamides) which are believed to be caused by additive incompatibility [40]. The authors have concluded that operating conditions of modern diesel engine fuel injectors in the presence of formic acid (a typical product of fuel oxidative break-down), were sufficient to promote reaction between polyisobutylene succinic imide (PIBSI) detergent additive and dimer acid lubricity additive. Another possibility to generate polyamide deposits, as indicated by the authors, was in situ dimerization of free fatty acids during periods of engine hot soak.

\section{GEOMETRY}

The influence of geometry on the amount of deposits in the injector holes was investigated by Argueyrolles et. al. [16]. Several geometrical parameters and their influence were examined, including outlet hole diameter, the conicity factor (Cf), and the inlet hole radius which is controlled by the level of "hydro grinding" $(\mathrm{He})$. A coking value is defined and the upper limit is set to $1.2 \% / 10 \mathrm{~h}$. Below are the definitions used by [16].

Cf Hole Conicity Factor

$$
C f=\frac{\text { Diameter }_{\text {ilete }}(\mathrm{um})-\text { Diameter }_{\text {outlet }}(\mathrm{um})}{10 \cdot \text { Hole Lengh }_{(\mathrm{mm})}}
$$

He Hole Hydro Grinding Level

$$
H e=\frac{F l o w_{a f f e r} \text { hudro grinding }-F l o w_{\text {before hydro grinding }}}{F l o w_{\text {before hydrog grinding }}}
$$

HF Nozzle Hydraulic Flow Rate (L/min)

Measured with $\triangle P=100 \mathrm{bar}$

\section{Coking Value}

Coking value $=$ Injected fuel flow rate loss $(\% / 10 h)$

Coking value $=10 \cdot \frac{\text { flow rate }_{\text {begining }}-\text { flow rate }_{\text {end of the rest }}}{\text { flow rate }_{\text {begining }} \cdot \text { test duration }}$

Fuel flow rate loss target $\leq 1.2 \% / 10 \mathrm{~h}$

In reference [16], different types of injectors with different geometries, see Table 2, were used in an engine test procedure. These different injectors produced different amounts of losses in their fuel flow rate, which are quantified by a coking value. The engine test procedure is a 30 hours constant run at 4000rpm and maximum power. The engine tests show clearly that injectors with high conicity, a small outlet hole diameter and a high hydro grinding level are leading to a high flow loss due to coking, see Figure 18, Figure 19 and Figure 20. In Figure 20 nozzle No. 1 has a bigger outlet diameter $(123 \mu \mathrm{m})$ than nozzle No. $6(110 \mu \mathrm{m})$.

Table 2: Nozzle Configurations [16]

\begin{tabular}{|c|c|c|c|c|c|}
\hline $\mathrm{N}^{\circ}$ & $\begin{array}{c}\text { Hole } \\
\text { number }\end{array}$ & $\begin{array}{c}\mathrm{HF} \\
(\mathrm{L} / \mathrm{min})\end{array}$ & $\mathrm{Cf}$ & $\mathrm{He}$ & $\begin{array}{c}\text { Outlet hole } \\
\text { diameter } \\
(\mu \mathrm{m})\end{array}$ \\
\hline $\mathrm{A} 1$ & 7 & 0.48 & 2.6 & 23 & 106 \\
\hline $\mathrm{A} 2$ & 7 & 0.48 & 1.8 & 14 & 107 \\
\hline $\mathrm{A} 3$ & 7 & 0.48 & 1.6 & 11 & 107 \\
\hline A4 & 7 & 0.48 & 1.5 & 11 & 108 \\
\hline $\mathrm{A} 5$ & 7 & 0.48 & 1 & 15 & 108 \\
\hline $\mathrm{A} 6$ & 7 & 0.52 & 2.4 & 19 & 110 \\
\hline $\mathrm{A} 7$ & 7 & 0.52 & 0.7 & 11 & 114 \\
\hline A8 & 6 & 0.52 & 0.4 & 12 & 123 \\
\hline
\end{tabular}




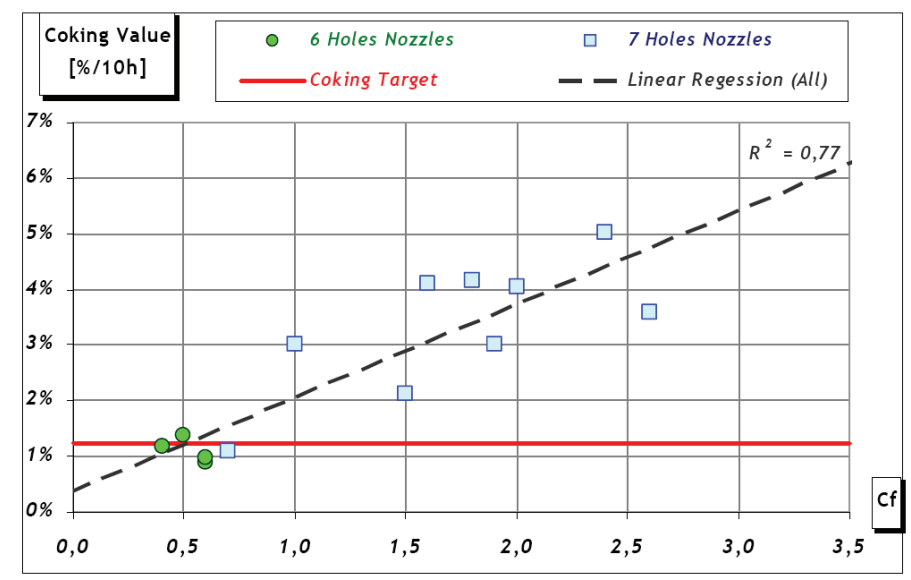

Figure 18: The effect of nozzle hole conicity on coking [16]

This shows a connection between the geometric design of the nozzle and its sensitivity to coking. As the geometric design influences the appearance of cavitation inside the injector holes, it is shown that the cavitation limits the amount of deposits. "The implosion of cavitation bubbles emitted from the cavitation films located at the hole entrance as they travel towards the hole exit, restricts the development of deposits on the wall" [16].

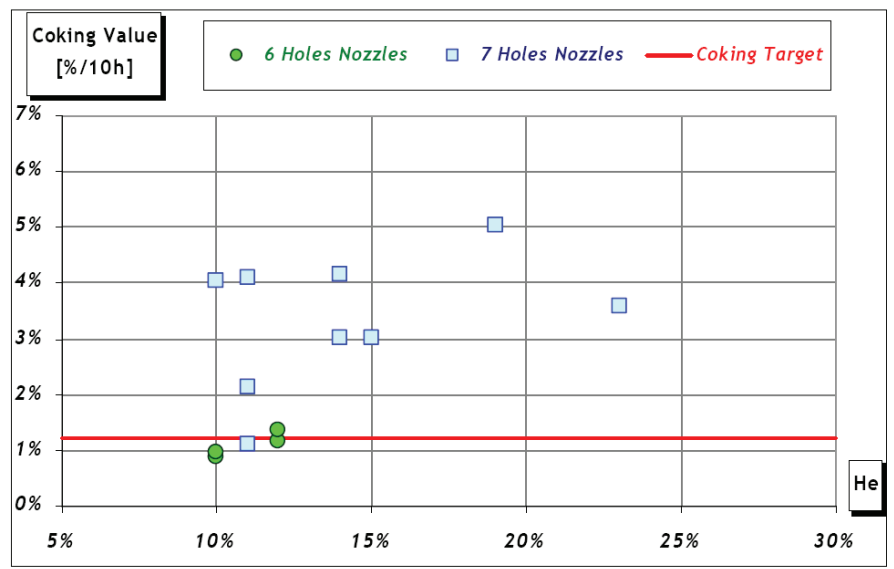

Figure 19: The effect of hydro grinding on coking, [16]

A "high pressure nozzle flow rig" is used to measure the flow loss due to cavitation which is defined by the value $(\Delta Q$ cav $) / Q$, equal to the loss of flow divided by the original flow where the flow is determined from the pressure drop across the nozzle. The same kind of nozzles which were used in the engine test runs were also investigated on the test rig. It is shown that a low $(\Delta$ Qcav)/Q value, which occurs with a low cavitation nozzle, shows a high coking value in the engine test, see Figure 21 . A limit for ( $\Delta \mathrm{Qcav}) / \mathrm{Q}$ is set at $2 \%$. Additionally the influences of conicity and hydro grinding on the $(\Delta Q$ cav $) / Q$ value are shown. To understand the results in a better way the injector holes are measured to get a more realistic geometry for a CFD simulation. A special silicone paste is used to measure the different radii inside the injectors. The simulation confirms the results.

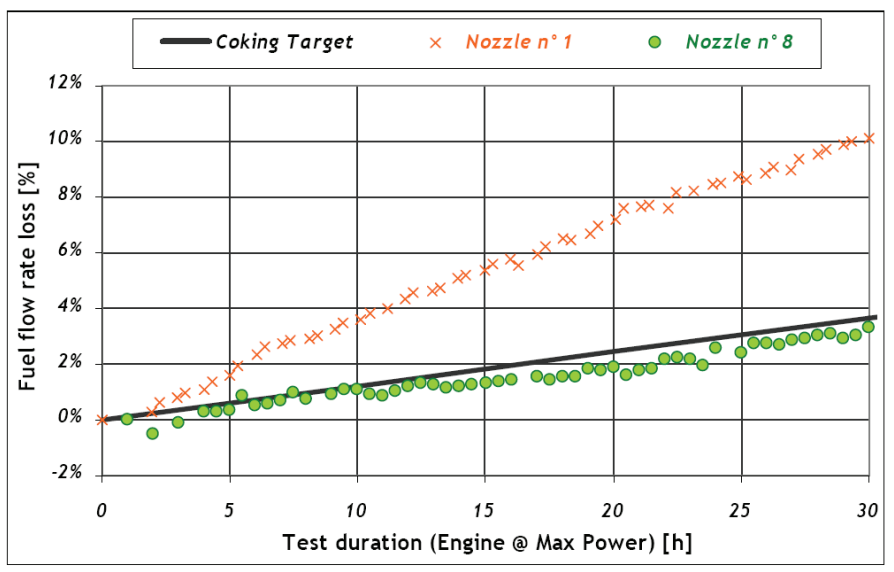

Figure 20: Fuel flow loss during test [16]

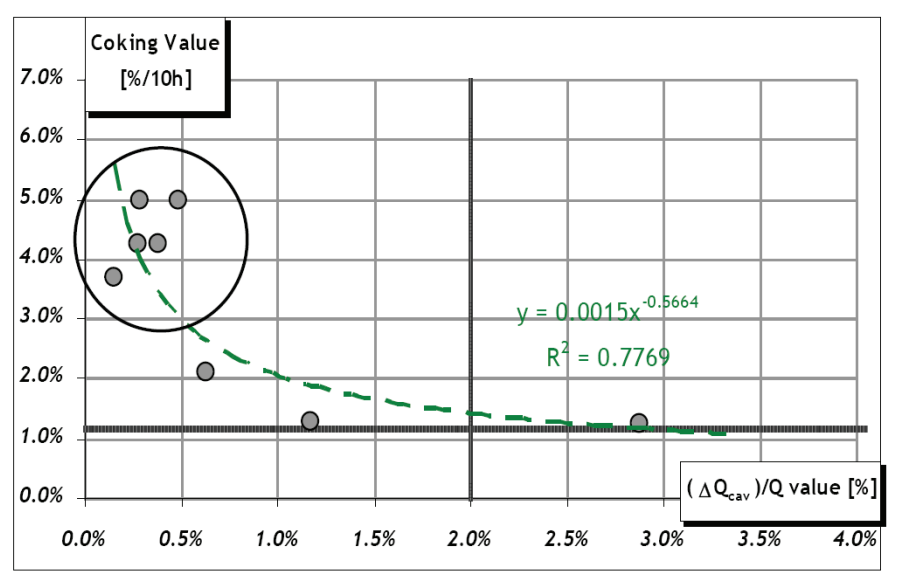

Figure 21: Fuel flow rate loss versus $(\Delta Q$ cav $) / Q$ value [16]

As a conclusion the paper "define[s] the minimum cavitation intensity required to avoid coking risk". So a compromise has to be made between the previous development efforts to optimise the fuel flow and ensuing coking problem, see Figure 22.

The above paper provides a very good investigation and discussion about the geometrical influence on the coking phenomenon. It also provides a possible solution for controlling the amount of deposits generated, which lies in allowing a certain amount of cavitation. This solution is, possibly within the control capability of the equipment manufactures and probably a good short-term possibility to control deposits. But it is not satisfying as it could not 
be a long-term solution. Furthermore Argueyrolles et al. [16] investigated one influence only and do not provide any explanation or further investigations on the basic mechanism of deposit formation.

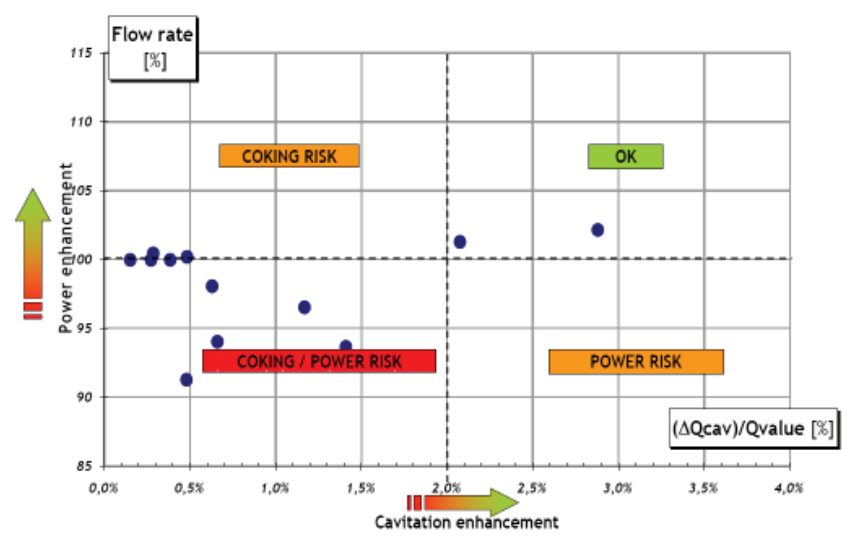

Figure 22: Trade off between hydraulic flow rate and cavitation [16]

\section{INFLUENCE OF TEMPERATURE AND CHEMICAL REACTIONS}

The influence of the temperature on the fouling or coking process is without doubt very important. During the injection, the fuel in the injection holes reaches very high temperatures as it travels towards the holes exit. The heat transfer between the fuel and the wall is influenced by variables such as shear layer thickness, wall roughness and turbulence. Also the absence of cavitation, as discussed in [16] and earlier in this paper, has an influence towards increasing the fuel temperature.

The paper by Argueyrolles et al. [16] mentions a critical temperature of $300^{\circ} \mathrm{C}$ on the injector tip to reach a serious amount of coking. This value is given without any reference. The review paper by Watkinson and Wilson [41] discuss the complicated chemical background of the fouling process e.g. in heat exchangers. It states that "fouling in organic mixtures can be caused by numerous reactions, including autoxidation, polymerization and thermal decomposition". Further the "autoxidation of hydrocarbons has been identified as the main source of unwanted deposits in reviews of fuel storage stability [...] in the temperature range from ambient to $300^{\circ} \mathrm{C}$. Deposition in oxygenated hydrocarbon systems above $250-300^{\circ} \mathrm{C}$ is dominated by thermal condensation and cracking reactions" [41]. In [42] by G. Lepperhoff and M. Houben it is stated that "Deposit locations at high temperature areas of an engine primarily result from non-metallic residuals from evaporating or burning fuel and/or lubricants".

The results of Mulard and China [17] indicate that a higher inlet temperature or higher coolant temperature leads to a higher amount of coking in an IDI engine. These temperature ranges, as mentioned by [41] are the expected ranges for the diesel fuel in an engine. The spill fuel warms up as it passes the injector and the pump. This can warm up the entire fuel in the system, which may lead to an increased reactivity and fouling. When biodiesel or blends of biodiesel are used, a raised temperature worsens its oxidation stability [21]. This together with the oxygen that the biodiesel contains may intensify the fouling reactions.

\section{POSSIBLE PHYSICAL MECHANISM}

In the paper by Caprotti et. al. [43] from 1993 a possible physical mechanism for deposits in an in-line injection system is described with several references (Figure 23).

The description, given by [43], is that after "closing of the nozzle in the high pressure part of the combustion process, liquid fuel is stored in the injector holes. This fuel expands during the expansion stroke due to temperature increase of the injector body. Therefore a liquid film is formed outside the holes at the nozzle tip. The high surface temperature at this location increases at the same time the evaporation of fuel components and degradation processes, leading to sticky deposits. Soot and high boiling hydrocarbons formed during combustion as well as lubricant components accumulate at the deposit interface (absorption, condensation, or physical compacting) increasing the rate of deposit formation. Further fuel expanding out of the nozzle holes is adsorbed in this sooty deposit and reacts to further increase deposit formation rate." This mechanism is supported by investigations shown in [42].

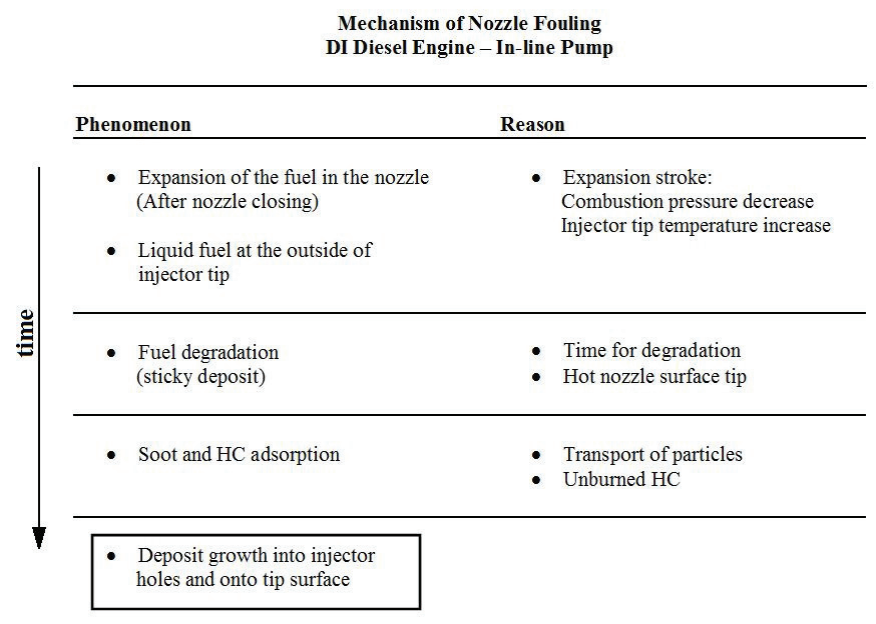

Figure 23: Mechanism of Nozzle Fouling, DI Diesel Engine - In-Line Pump [43] 


\section{CONCLUSION}

This report gives a review of published literature on the development and appearance of deposits in the injection holes of diesel injector nozzles and on the outside of the injector tip.

Three main influences on the creation of deposits are described in the literature. These are: the temperature, the fuel composition and the nozzle geometry. A possible physical mechanism for deposit formation is described and more literature will be considered on that.

Nozzle temperatures at around $300^{\circ} \mathrm{C}$ are forcing the fouling process through thermal condensation and cracking reactions. But the exact chemical reaction are, due to their complexity, not completely known or understood.

The design of the holes (hydro grinding level, conicity, roughness) influences the sensitivity to coking through cavitation. The implosion of cavitation bubbles limits the amount of coking.

If the fuel contains small amounts (1ppm) of zinc the amount of coking is increased. Zinc can be found in the fuel either because of contamination from the internal surfaces of the fuel system or added deliberately, for the study of deposit formation. It is not clear whether zinc acts catalytically to accelerate deposit formation or becomes part of the solid deposits. Pure biodiesel leads to a lot more deposits on the injector. Blends of biodiesel are showing a very unpredictable chemical behaviour and therefore their contribution to the creation of deposits is not clearly understood.

A possible physical mechanism for deposit formation (described in 1993) focuses on the fuel that remains in the nozzle holes after the end of the injection and on the influence of high temperature on the residual fuel.

\section{REFERENCES}

1. Sem T. R., "Investigation of Injector Tip Deposits on Transport Refrigeration Units Running on Biodiesel Fuel", SAE Technical Paper 2004-01-0091

2. Winterbone D. E., Clough E., Rao K. K., Richards P. Williams D., "The Effect of DI Nozzle Fouling on Fuel Spray Characteristics", SAE Technical Paper 922232

3. Richards P., Walker R.D., Williams D., "Fouling of Two Stage Injectors - An Investigation into Some Causes and Effects", SAE Technical Paper 971619

4. Blanco J. C., "Effect of Diesel Fuel Quality and Additives on Engine Performance - An Update", SAE Technical Paper 911710

5. Loest O., Ullmann J., Winter J. „Investigation on the Addition of FAME to Diesel Fuels“, DGMK Deutsche Wissenschaftliche Gesellschaft für Erdöl, Erdgas, und Kohle e.V., Research Report 639e, Hamburg, Germany, 2007

6. Leedham A., Caprotti R, Graupner O., Klaua T., "Impact of Fuel Additives on Diesel Injector Deposits", SAE Technical Paper 2004-01-2935

7. Caprotti R., Breakspear A., Graupner O., Klaua T., "Detergency Requirements of Future Diesel Injection System", SAE Technical Paper 2005-01-3901

8. Caprotti R., Breakspear A., Graupner O., Klaua T., Kohnen O., "Diesel Injector Deposits Potential on Future Fueling Systems", SAE Technical Paper 2006-01-3359

9. Graupner O., Klaua T., Caprotti R., Breakspear A., Schik A., Rouff C., "Injector Deposit Test For Modern Diesel Engines", TAE Symposium, 2005

10. Gallant T. R., Carman M. C., Gray J. T., Strete N. M., "Cummins L10 Injector Depositing Test to Evaluate Diesel Fuel Quality", SAE Technical Paper 912331

11. Gutman M., Tartakovsky L., Kirzhner Y, Zvirin Y., "Development of a Screening Test for Evaluating Detergent/Dispersant Additives to Diesel Fuels", SAE Technical Paper 961184

12. Panesar A., Martens A., Jansen L., Lal S., Ray D., Twilley M., "Development of a New Peugeot Xud9 10-Hour Cyclic Test to Evaluate the Nozzle Coking Propensity of Diesel Fuels", SAE Technical Paper 2000-01-1921

13. Williams R., "Development of a Nozzle-Fouling Test for Additive Rating in Heavy-Duty Di Diesel Engines", SAE Technical Paper 2002-01-2721

14. Blythe G. H., Flask C. A., "Development of an Image Analysis System to Rate Injectors from the Cummins L10 Injector Depositing Test", SAE Technical Paper 972902

15. Hawthorne M., Roos J. W., Openshaw M. J., "Use of Fuel Additives to Maintain Modern Diesel Engine Performance with Severe Test Conditions", SAE Technical Paper 2008-01-1806

16. Argueyrolles B., Dehoux S., Gastaldi P., Grosjean L., Levy F., Michel A., Passerel D., "Influence of injector nozzle design and cavitation on coking phenomenom", SAE 2007-01-1896, JSAE 20077184

17. Mulard P. P., China P. N., "Development of a Diesel Fuel Screening Test for Injector Nozzle Coking", SAE Technical Paper 922184

18. Mendoza M. C., Zhang Q., Hansen A. C., Reid J. F., "Injector Nozzle Coking With Oxygenated Diesel", SAE Technical Paper 2001-01-2016

19. Korus R. A., Jo J., Peterson C. L, "A Rapid Engine Test to Measure Injector Fouling in Diesel Engines Using Vegetable Oil Fuels", Journal of the American Oil Chemists' Society, Vol.62, No.11, p1563-1564, 1985

20. Barbour R., Arters D., Dietz J., Macduff M., Panesar A., Quigley R., "Diesel Detergent Additive Responses in Modern, High-Speed, Direct-Injection, Light-Duty Engines", SAE Technical Paper 2007-012001 
21. Shiotani H., Goto S., "Studies of Fuel Properties and Oxidation Stability of Biodiesel Fuel", SAE Technical Paper 2007-01-0073

22. BS ISO 4010, "Diesel engines - Calibrating nozzle, delay pintle type"

23. Caprotti R., Breakspear A., Klaua T., Weiland P., Graupner O., Bittner M., "RME Behaviour in Current and Future Diesel Fuel FIE's", SAE Technical Paper 2007-01-3982

24. Nwafor O. M. I., Rice G., "Performance of Rapeseed Oil Blends in a Diesel Engine", Applied Energy Vol. 54, No. 4, pp. 345-354, 1996, Elsevier Science

25. Labeckas G., Slavinskas S., "Performance of directinjection off-road diesel engine on rapeseed oil", Renewable Energy 31 (2006) 849-863, Elsevier

26. Fraer R., Dinh H.n, Proc K., McCormick R. L., Chandler K., Buchholz B., "Operating Experience and Teardown Analysis for Engines Operated on Biodiesel Blends (B20)", SAE Technical Paper 200501-3641

27. Huzayyin A.S., Bawady A.H., Rady M.A., Dawood A., "Experimental evaluation of Diesel engine performance and emission using blends of jojoba oil and Diesel fuel", Energy Conversion and Management 45 (2004) 2093-2112, Elsevier

28. Kalam M.A., Masjuki H.H., "Emissions and deposit characteristics of a small diesel engine when operated on preheated crude palm oil"; Biomass and Bioenergy 27 (2004) 289 - 297, Elsevier

29. Ribeiro N.M., Pinto A.C., Quintella C.M., da Rocha G.O., Teixeira L.S.G., Guarieiro L.L.N., do Carmo Rangel M., Veloso M.C.C., Rezende M.J.C., da Cruz R.S., de Oliveira A.M., Torres E.A., de Andrade J.B., "The Role of Additives for Diesel and Diesel Blended (Ethanol or Biodiesel) Fuels: A Review", Energy \& Fuels 2007, 21, 2433-2445

30. Danilov A.M., "Fuel additives: Evolution and Use in 1996-2000", Chemistry and Technology of Fuels and Oils, 2001, 37(6), 444-455

31. Quigley R., Barbour R. H., "Biodiesel Quality Improvement with Additive Treatment", SAE Technical Paper 2004-01-1859

32. Gairing M., Marriott J. M., Reders K. H., Reglitzky A. A., Wolveridge P.E., "The Effect of Modern Additive Technology on Diesel Fuel Performance", SAE Technical Paper 950252

33. Claar K. G., Blythe G. H., Pocinki S. B., "Diesel Fuel Properties and Additive Effects on DI Injector Deposit Formation, SAE Technical Paper 932738

34. Reading K., "A Study of the Clean-Up Activity of a High-Performance Diesel Fuel Detergent in IDI Engines", SAE Technical Paper 961942

35. Pistillo W.R., Gundic D.T., Kirchner-Jean T.M., "Counteracting Detrimental EGR Effects with Diesel Fuel Additive", SAE Technical Paper 2003-01-1915
36. Tomlinson A., Scherer B., Karakosta E., Oakey M., Danks T.N., Heyes D.M., Taylor S.E., "Adsorption properties of succinimide detergents on carbonaceous substrates", Carbon, 2000, 38, 13-28

37. Zerda T.W., Yuana X., Mooreb S.M., "Effects of fuel additives on the microstructure of combustion engine deposits", Carbon, 2001, 39, 1589-1597

38. Songa Y., Rena T., Fub X., Xu X., "Study on the relationship between the structure and activities of alkyl methacrylate - maleic anhydride polymers as cold flow improvers in diesel fuels", Fuel Processing Technology, 2005, 86, 641-650

39. Anastopoulos G., Lois E., Zannikos F., Kalligeros S., Teas C., "Influence of aceto acetic esters and dicarboxylic acid esters on diesel fuel lubricity", Tribology International, 2001, 34, 749-755

40. Ullmann J., Geduldig M., Stutzenberger H., Caprotti R. and Balfour G., "Investigation into the Formation and Prevention of Internal Diesel Injector Deposits", SAE Technical Paper 2008-01-0926

41. Watkinson A. P., Wilson D. I., "Chemical Reaction Fouling: A Review", Experimental Thermal and Fluid Science, 14:361-374, Elsevier Science Inc., New York, 1997

42. Lepperhoff G., Houben M., "Mechanisms of Deposit Formation in Internal Combustion Engines and Heat Exchangers", SAE Technical Paper 931032

43. Caprotti R., Fowler W. J., Lepperhoff G., Houben M., "Diesel Additive Technology Effects on Injector Hole Erosion/corrosion, Injector Fouling and Particulate Traps", SAE Technical Paper 932739

44. Lüft M., Bernhardt S., Velji A., Spicher U., "Optimization of Injection of Pure Rape Seed Oil in Modern Diesel Engines With Direct-Injection", SAE Technical Paper 2007-01-2031

45. Stephenson T., Davies C. W., Lloyd D. H., Wilson G. J., "Construction and Use of a Dual-Fuel, SplitEngine Commercial Vehicle for Demonstrating Fuel Effects on Performance", SAE Technical Paper 2007-24-0130

46. Richards P., Reid J., Tok L.-H., MacMillan I., "The Emerging Market for Biodiesel and the Role of Fuel Additives", SAE Technical Paper 2007-01-2033

47. Reading K., Evans T. M., "A Chassis Dynamometer Study of the Effects of Ago Detergent and Ignition Improver on Vehicle Fuel Consumption", SAE Technical Paper 942012

\section{CONTACT}

Andreas Birgel, Department of Mechanical Engineering, University College London, Torrington Place, London WC1E 7JE, UK, a birgel@meng.ucl.ac.uk 